\title{
Epidemiological study of leprosy in Malwani suburb of Bombay
}

\author{
R M CHATURVEDI \\ ICRC Anti-Leprosy Vaccine Project, 165 Railway Line, \\ Solapur-413001, India
}

Accepted for publication 1 October 1987

\begin{abstract}
Summary The present investigation was undertaken to study epidemiology of leprosy in Malwani, a western suburb of Bombay, which has a population of 63,321. A total of 691 cases were detected in a 4-year follow-up period between April 1979 and April 1983. The prevalence rate in schoolchildren was $13.88 \%$ and the peak incidence occurred in the age group 10-19 years. In this study, the females predominated the males with the male to female ratio being $1: 1 \cdot 33$. The disease was found to be more prevalent in the low socioeconomic group and in overcrowded families. Extremities were most commonly affected. A large number of cases occurred in contacts of infectious lepromatous patients. The exact reasons for this could not be ascertained from this rather small sample. It could be related to droplet infections or skin contact.
\end{abstract}

\section{Introduction}

Though leprosy was the first human disorder shown to be due to a microbe identified 100 years ago, it still continues to be a major public health problem, mostly in the developing countries of the world. It is estimated that there are 12-13 million leprosy patients in the world. The majority of them residing in Africa and Asia. Among individual nations, the largest number of leprosy patients (about 4 million) reside in India, where the estimated incidence is about 20,000-30,000 per year. ${ }^{1}$

In India, the prevalence of disease varies from place to place - the highest being in certain regions of Orissa, Tamil Nadu, Andhra Pradesh and Maharashtra. In Northern India, the prevalance is rather low. About $15-20 \%$ of patients are infectious, that is suffering from multibacillary forms of the disease. ${ }^{1}$ One of the distressing facts is that it affects pre-schoolchildren. The city of Bombay has a very high prevalence rate (13 per 1000). The large scale migration of people from outside in a way contributes to this high prevalence. In this expanding city, the suburbs and rural areas are getting urbanized at a very fast rate. One such area is Malwani with a population of 63,321 located in the western suburbs of Greater Bombay. Malwani has a well organized community health centre, developed by the KEM Hospital and Seth G.S. Medical College of Bombay. A number of preventive programmes have been undertaken including one for leprosy eradication. The aim of the present study is called the baseline information on the leprosy scene at Malwani, so that subsequent affects of control measures can be properly assessed. The present study was conducted over a 4-year period, April 1979 to April 1983. 


\section{Materials and methods}

The leprosy cases were registered through: (1) Mass house-to-house survey (a mass survey was done at the beginning of the programme); (2) school survey (a mass survey was done in July 1979 and repeated every year for new admissions. Suspected cases were also ref erred during regular school health check-ups); (3) household contact survey of the index cases (the contacts were examined once every 3 months); (4) referrals from health centres, dispensaries and general practitioners; and (5) self-reported cases having any sign and symptom of leprosy.

All the suspected cases during the mass survey and school survey were referred to the clinic. At the clinic they were examined clinically and bacteriologically. Once the diagnosis was made, the case history and examination findings of the patients were recorded on special case sheets, and an index number was given to each patient.

Doubtful cases were recorded on observation card and followed up at 3-month intervals. They were registered as regular patients after confirmation of the diagnosis.

Classification of the leprosy was done clinically and grouped according to Indian classification: (i) non-lepromatous; (ii) borderline; and (iii) lepromatous type. In the cases of borderline and lepromatous types, slit smears were obtained from the skin lesions and ear lobule.

\section{Results and discussion}

Table 1 shows the number of leprosy cases detected during various surveys.

The prevalence rate in the general population of Malvani is 10.91/1000. A high prevalence rate in the slums of North Bombay is also recorded in another study. ${ }^{2}$

The prevalence rate in school is $13 \cdot 81 / 1000$ which is higher than the general prevalence rate of the population. The higher prevalence rate in school is because a majority of cases $(53 \cdot 11 \%)$ are below 19 years (Table 2). The lepromatous type of cases are not seen in school as the majority$(89 \cdot 13 \%)$ of total lepromatous cases - are above 19 years (Table 2), or lepromatous cases may not be attending school. In the study area the majority of schools belong to the Municipal Corporation. A higher incidence of leprosy in Municipal Schools has also been reported in other studies. ${ }^{3-5}$ In this study $21.56 \%$ of cases are detected through school surveys, so school surveys are a major tool in leprosy control programmes.

The peak incidence is observed in the age group 10-19 years. The other workers have reported the peak incidence in the age group 20-29. No explanation can be offered, at the moment, for these differences. The incubation period of leprosy is very long, so an extensive surveillance programme

Table 1

\begin{tabular}{|c|c|c|c|c|c|c|c|c|}
\hline \multirow[b]{2}{*}{ Mode of detection } & \multicolumn{2}{|c|}{$\mathrm{T}$} & \multicolumn{2}{|r|}{ B } & \multicolumn{2}{|c|}{$\mathrm{L}$} & \multicolumn{2}{|c|}{ Total } \\
\hline & No. & $\%$ & No. & $\%$ & No. & $\%$ & No. & $\%$ \\
\hline Mass survey & 229 & $41 \cdot 86$ & 38 & $38 \cdot 78$ & 26 & $56 \cdot 52$ & 293 & $42 \cdot 40$ \\
\hline School survey & 130 & $23 \cdot 77$ & 19 & $19 \cdot 39$ & 0 & 0.00 & 149 & $21 \cdot 56$ \\
\hline Contact survey & 50 & $9 \cdot 14$ & 6 & $6 \cdot 12$ & 4 & $8 \cdot 70$ & 60 & 8.69 \\
\hline Referrals and self-reported & 138 & $25 \cdot 23$ & 35 & $35 \cdot 71$ & 16 & $34 \cdot 78$ & 189 & $27 \cdot 35$ \\
\hline Total & 547 & 100 & 98 & 100 & 46 & 100 & 691 & $100 \cdot 00$ \\
\hline Percentage & \multicolumn{2}{|c|}{$79 \cdot 16$} & \multicolumn{2}{|c|}{$14 \cdot 18$} & \multicolumn{2}{|c|}{$6 \cdot 66$} & \multicolumn{2}{|c|}{$100 \cdot 00$} \\
\hline
\end{tabular}

Total number of schoolchildren examined: 10,789 .

The prevalence rate in school: $13 \cdot 81 / 1000$. 
Table 2. Prevalence of leprosy in different age groups among male and female cases and types of leprosy

\begin{tabular}{|c|c|c|c|c|c|c|c|c|c|c|c|c|c|c|c|c|c|c|}
\hline \multirow{3}{*}{$\begin{array}{l}\text { Age } \\
\text { Group }\end{array}$} & \multicolumn{4}{|c|}{$\mathrm{T}$} & \multicolumn{4}{|c|}{ B } & \multicolumn{4}{|c|}{$\mathrm{L}$} & \multicolumn{4}{|c|}{ Total } & \multirow{2}{*}{\multicolumn{2}{|c|}{$\begin{array}{c}\text { Total } \\
\text { Male and Female }\end{array}$}} \\
\hline & \multicolumn{2}{|c|}{ Male } & \multicolumn{2}{|c|}{ Female } & \multicolumn{2}{|c|}{ Male } & \multicolumn{2}{|c|}{ Female } & \multicolumn{2}{|c|}{ Male } & \multicolumn{2}{|c|}{ Female } & \multicolumn{2}{|c|}{ Male } & \multicolumn{2}{|c|}{ Female } & & \\
\hline & No. & $\%$ & No. & $\%$ & No. & $\%$ & No. & $\%$ & No. & $\%$ & No. & $\%$ & No. & $\%$ & No. & $\%$ & No. & $\%$ \\
\hline $0-9$ & 64 & $29 \cdot 77$ & 68 & $20 \cdot 48$ & 8 & $15 \cdot 09$ & 6 & $13 \cdot 33$ & 0 & $0 \cdot 00$ & 1 & $5 \cdot 56$ & 72 & $24 \cdot 33$ & 75 & 18.99 & 147 & $21 \cdot 27$ \\
\hline $10-19$ & 93 & $43 \cdot 26$ & 96 & 28.92 & 19 & $35 \cdot 86$ & 8 & $17 \cdot 78$ & 3 & $10 \cdot 71$ & 1 & $5 \cdot 56$ & 115 & $38 \cdot 85$ & 105 & $26 \cdot 58$ & 220 & $31 \cdot 84$ \\
\hline $20-29$ & 15 & 6.98 & 64 & $19 \cdot 28$ & 5 & $9 \cdot 43$ & 10 & $22 \cdot 22$ & 2 & $7 \cdot 14$ & 4 & $22 \cdot 22$ & 22 & $7 \cdot 43$ & 78 & $19 \cdot 75$ & 100 & 14.47 \\
\hline $30-39$ & 23 & $10 \cdot 70$ & 16 & 18.07 & 3 & 5.66 & 11 & 24.45 & 7 & $25 \cdot 10$ & 4 & $22 \cdot 22$ & 33 & $11 \cdot 15$ & 75 & 18.99 & 108 & 15.63 \\
\hline $40-49$ & 7 & $3 \cdot 25$ & 24 & $7 \cdot 23$ & 7 & $13 \cdot 21$ & 6 & $13 \cdot 33$ & 6 & $21 \cdot 43$ & 4 & $22 \cdot 22$ & 20 & $6 \cdot 76$ & 34 & $8 \cdot 61$ & 54 & $7 \cdot 82$ \\
\hline $50-59$ & 9 & $4 \cdot 19$ & 11 & $3 \cdot 31$ & 8 & $15 \cdot 09$ & 3 & 6.67 & 5 & $17 \cdot 86$ & 3 & 16.66 & 22 & $7 \cdot 43$ & 17 & $4 \cdot 30$ & 39 & 5.64 \\
\hline 60 or more & 4 & $1 \cdot 86$ & 9 & $2 \cdot 71$ & 3 & $5 \cdot 66$ & 1 & $2 \cdot 2$ & 5 & $17 \cdot 86$ & 1 & $5 \cdot 56$ & 12 & 4.05 & 11 & $2 \cdot 78$ & 23 & $3 \cdot 31$ \\
\hline Total & 215 & 100 & 332 & 100 & 53 & 100 & 45 & 100 & 28 & 100 & 18 & 100 & 296 & 100 & 395 & 100 & 691 & 100 \\
\hline Mean (years) & $17 \cdot 9$ & & $22 \cdot 8$ & & $27 \cdot 9$ & & $28 \cdot 0$ & & $33 \cdot 2$ & & $36 \cdot 7$ & & $22 \cdot 1$ & & $24 \cdot 0$ & & & \\
\hline SD & & $14 \cdot 8$ & \pm & $17 \cdot 9$ & & $19 \cdot 2$ & & $15 \cdot 2$ & & $18 \cdot 2$ & & $5 \cdot 1$ & & $17 \cdot 3$ & & & & \\
\hline Sex ratio & & 647 & 000 & & & 1177 & 1000 & & & 155 & 1000 & & & 749 & 000 & & & \\
\hline $\mathrm{Z}$ & & 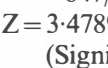 & $\begin{array}{l}p<0 \text {. } \\
\text { cant })\end{array}$ & & & $\begin{array}{r}\mathrm{Z}=1 \cdot 15 \\
(\text { Not si }\end{array}$ & $\begin{array}{l}p>0 \\
\text { ifican }\end{array}$ & & & $\begin{array}{l}=0.72 \\
\text { Not si }\end{array}$ & $\begin{array}{l}p>0 \\
\text { ifican }\end{array}$ & & & $\begin{array}{l}=1 \cdot 57 \\
\text { Not sig }\end{array}$ & $\begin{array}{l}p>0 \\
\text { ifican }\end{array}$ & & & \\
\hline
\end{tabular}


may show peak incidence of infection in an earlier age group. The mean age of infection in females is higher than in males in the non-lepromatous type of infection.

The male to female ratio is $1: 1 \cdot 33$. Other studies quoted earlier show the predominance of male cases over female cases. The female cases are seen more where lepromatous cases are less (in this study lepromatous cases are only $6 \cdot 6 \%$ of the total cases) (Table 1 ). This confirms the findings of another study. ${ }^{6}$

The male:female ratio in lepromatous cases is $1 \cdot 56: 1$, and in borderline the ratio is $1 \cdot 18: 1$. The Marshall's study shows the same pattern. ${ }^{8}$ In non-lepromatous the females predominate over males.

The male:female ratio in the Malwani population is $1 \cdot 16: 1 .^{8}$ So there is no significant predominance of either sex in the general population. There is practically no sex difference up to the age of 19 years as there are fewer infectious cases below 19 years of age.

There are several factors which influence the sex predominance in the endemic area. The main factor causing the sex difference is opportunity for contact and practically no difference is noted when the opportunity for contact remains the same.

The higher female ratio can be explained on the basis that males are at work during the day time, while the mother or older females remain in contact with children at home $(53 \cdot 11 \%$ of cases are below the 19 years age group).

Until it can be shown that the lepromatous rate is greater in males in childhood, it can be assumed that this sex difference may be due to the difference in the susceptibility. ${ }^{6}$

Table 3. Religion wise distribution of leprosy cases

\begin{tabular}{|c|c|c|c|c|}
\hline \multirow[b]{2}{*}{ Religion } & \multicolumn{2}{|c|}{ Leprosy cases } & \multicolumn{2}{|c|}{ Malvani population ${ }^{8}$} \\
\hline & No. & $\%$ & No. & $\%$ \\
\hline Hindu & 331 & $47 \cdot 90^{*}$ & 36093 & $57 \cdot 00^{*}$ \\
\hline Muslim & 318 & $46.02 \dagger$ & 23428 & $37 \cdot 0 \dagger$ \\
\hline Christians & 39 & $5.65 \ddagger$ & 3102 & $4.9 \ddagger$ \\
\hline Others & 3 & 0.44 & 698 & $1 \cdot 1$ \\
\hline Total & 691 & 100 & 63321 & 100 \\
\hline
\end{tabular}

* Z, $4.8046 p<0.001$ significantly less.

$\mathrm{Z}, 2.6234 p<0.05$ significantly less.

Z, $0.8740 p>0.05$ not significant (no difference).

Table 4. Distribution of cases according to the type of dwelling

\begin{tabular}{|c|c|c|c|c|}
\hline \multirow{2}{*}{$\begin{array}{l}\text { Type of } \\
\text { dwelling }\end{array}$} & \multicolumn{2}{|c|}{ Leprosy cases } & \multicolumn{2}{|c|}{$\underset{\text { tion }}{\text { Malvani popula }}$} \\
\hline & No. & $\%$ & No. & $\%$ \\
\hline Zopadapatti & 463 & $67 \cdot 01^{*}$ & 40557 & $64 \cdot 05^{*}$ \\
\hline Chawls & 221 & $31.98 \dagger$ & 21852 & $34 \cdot 51 \dagger$ \\
\hline Individual tenements & 7 & $1 \cdot 01$ & 912 & $1 \cdot 34$ \\
\hline Total & 691 & 100 & 63321 & 100 \\
\hline
\end{tabular}

* Z, $1.4954 p>0.05$ not significant.

$\dagger \mathrm{Z}, 1.2887 p>0.05$ not significant. 
The prevalence of leprosy is greater among the Muslim population. Both the communities live in the same socioeconomic settings, however, the average size of Muslim families is larger than Hindu families. ${ }^{9}$ (This was also observed in our contact study.) Overcrowding could be a very important factor and may be responsible for a higher prevalence in Muslims (see Table 3).

There is practically no significance in the type of dwelling (see Table 4). This is why all the slums of Bombay have different prevalence rates, ${ }^{12}$ though the main structure of residence in the slum is zopadapatti.

The majority of the cases belong to the low income group (Rs. 0-50) (see Table 5). The average per capita income per month is Rs. 62/- whereas the lowest income per capita per month is Rs. 70/in the general population of India. ${ }^{10}$ There is usually an attempt to correlate socioeconomic status to the incidence of leprosy. However, the former can not be a cause, as unemployment due to disease and disability keeps these families in the low income group.

Unemployment is $17 \cdot 22 \%$ (see Table 6 ). This is because of disability produced by the disease and also because once the patient's diagnosis is known he is removed from his job. The exact number of the patients removed from their jobs due to disease or disability is not known, for that long term follow-up is required.

The majority of patients show a single lesion (see Table 7). Also in school surveys most of the children show a single lesion. Often the single lesion remains in the silent form and the patient

Table 5. Distribution of cases according to per capita income per month

\begin{tabular}{|c|c|c|c|c|}
\hline \multirow{2}{*}{$\begin{array}{l}\text { Monthly income } \\
\text { (Rupees) }\end{array}$} & \multicolumn{2}{|c|}{ Cases } & \multicolumn{2}{|c|}{ Malvani population ${ }^{8}$} \\
\hline & No. & $\%$ & No. & $\%$ \\
\hline $0-50$ & 327 & $47 \cdot 32 \dagger$ & 15704 & $24 \cdot 8 \dagger$ \\
\hline $51-100$ & 283 & $40 \cdot 96$ & 27861 & $44 \cdot 0$ \\
\hline $101-250$ & 70 & $10 \cdot 13$ & 15323 & $24 \cdot 2$ \\
\hline More than 250 & 11 & $1 \cdot 59$ & 4433 & $7 \cdot 0$ \\
\hline Total & 691 & 100 & 63321 & 100 \\
\hline
\end{tabular}

* Z, $11.808 p<0.001$ (highly significant).

Average income per month: Rs. 62/- per capita (patient).

Average income per month: Rs. $99 \cdot 05$ per capita (Malvani population).

Table 6. Occupation of cases

\begin{tabular}{lrr}
\hline Occupation & Number & \multicolumn{1}{c}{$\%$} \\
\hline Unskilled worker & 111 & $16 \cdot 06$ \\
Skilled worker & 33 & $4 \cdot 77$ \\
Clerical cadre & 27 & $3 \cdot 91$ \\
Trader & 42 & $6 \cdot 08$ \\
Student & 169 & $24 \cdot 46$ \\
Housewife & 190 & $27 \cdot 50$ \\
Unemployed & 119 & $17 \cdot 22$ \\
\hline Total & 691 & 100 \\
\hline
\end{tabular}


Table 7. The distribution of cases according to the number of lesions

\begin{tabular}{|c|c|c|c|c|c|c|}
\hline \multirow[b]{2}{*}{ No. of lesions } & \multicolumn{2}{|c|}{ Male } & \multicolumn{2}{|c|}{ Female } & \multicolumn{2}{|c|}{ Total } \\
\hline & No. & $\%$ & No. & $\%$ & No. & $\%$ \\
\hline Single lesion & 157 & $57 \cdot 04$ & 240 & $60 \cdot 76$ & 397 & $57 \cdot 45$ \\
\hline More than one lesion & 139 & $46 \cdot 96$ & 155 & $39 \cdot 24$ & 294 & $42 \cdot 55$ \\
\hline Total & 296 & 100 & 395 & 100 & 691 & 100 \\
\hline
\end{tabular}

Table 8. The distribution of lesions according to the sites of lesion in the cases having a single lesion

\begin{tabular}{|c|c|c|c|c|c|c|}
\hline \multirow[b]{2}{*}{ Sites of lesion } & \multicolumn{2}{|c|}{ Male } & \multicolumn{2}{|c|}{ Female } & \multicolumn{2}{|c|}{ Total } \\
\hline & No. & $\%$ & No. & $\%$ & No. & $\%$ \\
\hline Arm & 47 & $29 \cdot 95$ & 71 & $29 \cdot 59$ & 118 & $29 \cdot 72$ \\
\hline Leg & 39 & $24 \cdot 84$ & 50 & $20 \cdot 83$ & 89 & $22 \cdot 42$ \\
\hline Thigh including hip and buttock & 32 & $20 \cdot 38$ & 33 & $13 \cdot 75$ & 65 & $16 \cdot 37$ \\
\hline Back & 15 & $9 \cdot 55$ & 48 & $20 \cdot 00$ & 63 & $15 \cdot 87$ \\
\hline Pectoral region & 5 & $3 \cdot 18$ & 8 & $3 \cdot 33$ & 13 & $3 \cdot 27$ \\
\hline Epigastric region & 5 & $3 \cdot 18$ & 9 & $3 \cdot 75$ & 14 & $3 \cdot 53$ \\
\hline Face & 14 & 8.92 & 21 & 8.75 & 35 & $8 \cdot 82$ \\
\hline Total & 157 & 100 & 240 & 100 & 397 & 100 \\
\hline
\end{tabular}

ignores it. Many cases are also detected during the general examinations of patients in hospitals who have been admitted for other complaints. " That is why mass survey school surveys and health education forms an effective tool for identification of cases, which is a pre-requisite for understanding control programmes. ${ }^{12}$

Only the site where the lesion appears first is of significance. In the case of multiple lesions, it would be difficult to find out from the patient the exact site of the first lesion, hence the patients having a single lesion were selected for such analysis (see Table 8). The commonest sites are arm, leg, thigh and buttocks. These are the sites in the body which receive maximum trauma, friction and inflammation, and these sites also have more skin-to-skin contact. However, there is variation among the sites in different age groups and in different regions. ${ }^{13}$ No explanation can be offered, at the moment, for these regional differences.

The epigastric and pectoral regions show very few lesions as these are well-protected areas of the body.

Out of the five deformities of the eyes, three were of the lagophthalmos type and two were of blindness, which was caused by persistent iridocyclitis and exposure keratitis due to paralysis of the Vth cranial nerve (see Table 9). Chronic iridocyclitis is a common phenomenon which can lead to blindness in borderline lepromatous cases. ${ }^{14}$

The observation period of this study was 4 years. As the incubation period of leprosy is uncertain, long-term observation is required to find out the impact of transmission of the disease among household contacts. The prevalence rate of 19.30/1000 among contacts was found to be significantly higher than the general prevalence rate of $10 \cdot 91 / 1000$ for Malvani.

The incidence of infectivity is greater among the contact cases of lepromatous and borderline 
Table 9. Type of deformity in male and female cases

\begin{tabular}{|c|c|c|c|c|c|c|}
\hline \multirow[b]{2}{*}{ Type of def ormity } & \multicolumn{2}{|c|}{ Male } & \multicolumn{2}{|c|}{ Female } & \multicolumn{2}{|c|}{ Total } \\
\hline & No. & $\%$ & No. & $\%$ & No. & $\%$ \\
\hline Eye & 3 & $4 \cdot 12$ & 2 & $3 \cdot 58$ & 5 & $3 \cdot 88$ \\
\hline Hand & 27 & $36 \cdot 98^{*}$ & 28 & $50 \cdot 00^{*}$ & 55 & $42 \cdot 64$ \\
\hline Foot & 33 & $45 \cdot 21 \dagger$ & 20 & $35 \cdot 71 \dagger$ & 53 & $41 \cdot 08$ \\
\hline Hand and Foot & 10 & $13 \cdot 69$ & 6 & $10 \cdot 71$ & 16 & $12 \cdot 40$ \\
\hline Total & 73 & 100 & 56 & 100 & 129 & 100 \\
\hline
\end{tabular}

* Z, $0.98 p>0.05$ not significant.

$\dagger \mathrm{Z}, 1.76 p>0.05$ not significant.

Table 10. Distribution of contact cases in different types of index cases

\begin{tabular}{ccccccc}
\hline $\begin{array}{c}\text { Nype of } \\
\text { index cases } \\
\text { contacts } \\
\text { examined }\end{array}$ & T & B & L & Total & $\begin{array}{c}\text { Incidence } \\
\text { of infectivity } \\
(\%)\end{array}$ \\
\hline T & 2530 & $43(86)$ & $0(0)$ & $0(0)$ & $43(71 \cdot 67)$ & $1 \cdot 70$ \\
B & 450 & $7(14)$ & $5(83 \cdot 33)$ & $1(25)$ & $13(21 \cdot 67)$ & $2 \cdot 87$ \\
L & 129 & $0(0)$ & $1(16 \cdot 67)$ & $3(75)$ & $4(6 \cdot 66)$ & $3 \cdot 10$ \\
\hline Total & 3109 & $50(100)$ & $6(100)$ & $4(100)$ & $60(100)$ & $1 \cdot 93$ \\
\hline
\end{tabular}

Figures in brackets indicate percentages.

cases than the non-lepromatous type, indicating that contacts of lepromatous cases are at higher risk (see Table 10). The contacts of lepromatous cases are fewer as the majority of lepromatous cases stay alone and away from their families. The contact case findings are similar to the findings of Doull (1961). ${ }^{15}$

Lepromatous cases are not seen among contacts of non-lepromatous cases. Three lepromatous cases are recorded among the contacts of lepromatous 'Index case'. This indicates that the disease is infectious and proves the concept of contact transmission.

\section{Conclusions}

The epidemiological study of leprosy in Malvani has shown a few minor differences in the pattern of leprosy in comparison with studies elsewhere.

These are: (a) reversal in sex ratio, the male and female ratio is $1: 1 \cdot 33$; (b) peak incidence of disease is in a younger age group of 10-19 years; (c) the proportion of lepromatous cases is $(6 \cdot 6 \%)$ less than figures for all India; and (d) the deformity rate (18.67\%) was found to be lower than elsewhere.

\section{References}

1 Report of the working group on the eradication of leprosy, February, 1982, Ministry of Health and Family Welfare, Government of India, New Delhi, p. 2 \& 10. 
2 Revankar, CR et al. Leprosy survey in Urban slums. Possibility for epidemiological investigations. Lepr Rev, 1982; 53: 99-104.

${ }^{3}$ Ganapati et al. Leprosy among school children in greater Bombay. Results of surveys. Lepr India, 1973; 45: $151-62$.

${ }^{4}$ Pandya et al. Childhood leprosy: Study of prevalence rate and clinical aspect through school survey in Bombay. Lepr India, 1976; 48: 645-60.

5 Koticha, KK. Case detection through school surveys in Greater Bombay. Lepr India, 1976; 48: No. 4 (Suppl.) 819-24.

6 Newell, KW. An epidemiologists view of leprosy, Bull WHO, 1966; 34: 827-57.

7 Marshall et al. Prevalence of leprosy among slum dwellers. Lepr India, 1981; 53: 78.

8 Review of health care delivery system. Malvani 1977, 1982. Seth G.S. Medical College \& KEM Hospital, Bombay.

9 Park, JE et al. Textbook of Prevalence and Social Medicine, India: Banarsidas Bhanot, 461-71, 1981.

10 International Planned Parenthood Federation. People, 1978; 5(3): 3.

11 Ganapati R et al. Prevalence of leprosy among indoor patients in General Hospital. A survey in Bombay. Lepr Rev, 1980; 51: 325-8.

12 Mani, RS. Impotency of systematic school survey in urban leprosy control. Lepr India, 1976; 48: (Suppl) 813-17.

13 Sardari Lal et al. Epidemiology of leprosy in Pondicherry. Lepr India, 1982; 54: 677-84.

14 Doull, JA. The epidemiology of leprosy. Present status and problems. Int J Lepr, 1962; 30: 48-66.

15 ffytche, TJ. The eye and leprosy. Editorial. Lepr Rev, 1981; 52: 111-19.

\section{TEACHING MATERIALS AND SERVICES}

\section{'Hansenologia'; Dermatologia Tropical; textbook in Portuguese}

This excellent book in Portuguese, written by Dr Sinesio Talhari and Dr Rene Garrido Neves, both from Brazil, deserves further publicity. The edition we have is dated 1984, but it may havebeen revised. It is a strongly bound paperback of about 100 pages, covering all basic aspects of leprosy (but note that the use of 'Hansenology' and similar derivatives is important in their country) in a most competent and up-to-date manner. It is prof usely illustrated in black and white, and colour pictures. In view of the scarcity of good material in Portuguese, this book deserves serious attention and wider distribution, including Angola, Mozambique, Cape Verde and Guinea Bissau. Enquiries to Dr Sinesio Talhari, Servicio de Dermatologia, Faculdade de Medicina, 69000 , Manaus, Amazonas, Brasil.

\section{WHO Training in leprosy}

This document; WHO/CDS/LEP/86.2 (English language) was produced by WHO in 1986 and is available on application to the Department of Publications, WHO, 1211 Geneva 27, Switzerland. It was written as a collaborative effort between Miss P J Neville, Education and Training Secretary, the Leprosy Mission International, London; Dr W Felton Ross, Medical Adviser, American Leprosy Missions Inc., USA; the Leprosy Unit, Division of Communicable Diseases, WHO, Geneva. The four main sections cover: introduction, training health personnel in leprosy, teaching and training considerations, teaching/learning materials on leprosy.

\section{Self-instructional packages in medical education}

The September 1986 issue of the Newsletter from the School of Medical Education, the University of New South Wales, P.O. Box 1, Kensington, NSW, 2033, Australia carries an interesting article on the above subject by May Wong. Such packages are defined in the opening paragraph as "collections of learning items that have been designed to guide the learner in a structured manner through one or more learning tasks. The learning materials are organized in such a way that they provide stimuli, learning activites [responses and practice] feedback and . assessment and allow the learners to function with little or no intervention from the instructors.'

(This publication merits further study. In the absence of experienced and credible teachers for the subject of leprosy in most endemic areas, this approach may have much to commend it.-Editor.) 